\title{
Relational data structure of the coating database from the "Coatings \& High Temperature Corrosion Data Bank" (*)
}

\author{
Stanislaw Komornicki $\left({ }^{1}\right)$ and Roland Streiff $\left({ }^{2}\right)$ \\ ( $\left.{ }^{1}\right)$ Academy of Mining and Metallurgy, 30-059 Krakow, Poland \\ $\left({ }^{2}\right)$ Université de Provence, 13331 Marseille cedex 3, France
}

\begin{abstract}
A data bank on coatings and high temperature corrosion, called C\&HTC-DATA, has been created and will be operated by the Corrosion Data Centre at the University of Provence in Marseille - France. This data bank has been created to help to choose coatings for specific applications, knowing their fabrication process characteristics and their protectivity characteristics. C\&HTC-DATA will include five databases, viz. 1) a bibliographic reference data base, 2) a coatings database, 3) a corrosion database, 4) an alloy composition database, and 5) a directory of addresses of companies and researchers involved in the field of high temperature corrosion and protection of materials. Four of these databases have been installed by the ORACLE Relational Data Base Management System (R.D.B.M.S.) and are in the $\beta$ stage of "on line" operation. In this paper the relational structure of the factual data on coatings in the coating database is discussed.
\end{abstract}

\section{Introduction.}

High temperature coatings are mandatory to protect structural alloys and to extend service life of hot section components of gas turbines and energy systems operating in aggressive environments which are subjected to various attacks such as oxidation, sulphidising, carburising, chlorination, erosion and hot corrosion induced by molten salts. The need to protect materials has resulted in a wide variety of corrosion-resistant coatings which are applied by a number of different processes, and are specific for different applications and corrosive environments.

The impressive variety of high temperature protective coatings which has been reviewed in this Conference [1], makes the selection of the appropriate coating for a specific application a challenging and hazardous task, especially since, in addition, information on coating formulations, deposition methods and service performances is either scattered throughout the literature or regarded as proprietary by coating manufacturers and suppliers.

Moreover, the behaviour of coatings and high temperature materials in service or in simulated service conditions has been increasingly researched during the last decades and has been recorded in an expanding number of scientific journals and periodicals, in conferences and symposium papers [2], and in a variety of technical reports. There is such a wealth of data that much information of direct value to the design or engineering of high temperature energy systems is inevitably lost or overlooked.

Hence there is a need for easily available, reliable information and for systems with the capability to appraise this information. To answer this concern the "Coatings and High Temperature Corrosion Data Bank" (designated C\&HTC-DATA) has been created with the aim

(*) Invited paper. 
of helping to choose coatings for specific applications, knowing their fabrication process characteristics and their protectivity characteristics.

The early stage of building of this data bank have been presented in previous papers [3-6] and we will, in this paper, discuss more particularly the data relational schema (DRS) of the data bank and the relational structure of the data on coatings.

\section{File structure of the data bank.}

The data scope for which a database should be designed is a function of the intended application of the database (the "user model") and of the intended integration with a knowledge base or expert system. Although this leads to a number of variations, it will be necessary for most systems to represent data generated by testing and to document these test results adequately for the purpose of the database. Data on materials corrosion have various peculiarities; thus the behaviour of an engineering alloy or of a coating, as determined by a typical corrosion test, can be influenced by several hundred parameters which have their origin in the characteristics of the material (or the coating) and its production process, the test method and conditions, the testing control and environmental parameters, the specimen characteristics such as surface preparation, geometry, and many more.

The main subdivision of a coating characteristic and properties data scope can be based on the formal description of four classes of data: (1) coating characteristics, (2) substrate alloy characteristics, (3) corrosion characteristics, (4) data source (or bibliographic references).

The implementation of C\&HTC-DATA has followed the usual schema of building any materials data bank [7] of which the first step is the definition of the Data Conceptual Schema (DCS). This includes the definition of the metadata, i.e. the definition of the entities composing the databases and of the associations or relationships linking these entities. Metadata are data about data or description of the data in a database.

The complete list of metadata currently defined for these four classes of data has already been published elsewhere [3]. The metadata for each class of data may be summarised briefly as follows.

1) Coatings characteristics which includes the nominal composition, deposition process, surface treatment, pack composition, coating thickness and so on.

2) Substrate alloys which includes the alloy name, its nominal composition, and its structure.

3) Corrosion characteristics which includes corrosion environment, corrosion type, corrosion product, effect of surface treatment and so on.

4) Bibliographic references which includes the usual references for any abstract or report, source, language, publication year, volume, and so on..., and the affiliation of the authors with the address.

This has resulted in a file structure for the data bank which includes five databases composed of a number of tables of which any one represent a single metadata or a group of metadata $[5,6]$.

- A coatings database to collect factual data on protective coatings deposition characteristics, properties and commercial status.

- A corrosion database to collect factual data on high temperature corrosion of coatings and other materials.

- An alloys numerical database to collect data on the composition of alloys, including both substrate alloys of specified coatings included in the coating database and corrosion substrate alloys from data analysed in the corrosion database. 
- A bibliographic references textual database to collect all the available literature (journals, reports, books and proceedings) on coatings and high temperature corrosion.

- A directory to collect world-wide addresses on laboratories, research institutes involved in high temperature corrosion and protection research and companies producing high temperature materials and coatings. This directory has been created because there is a high demand for information about the laboratories working in the field to know "who is doing what". Data are mainly coming from addresses of authors of abstracts, reports and patents from the bibliographic database, or from addresses of inventors or manufacturer of coatings from the coatings database.

\section{Relational data structure of coatings data.}

3.1 The RELATiOnal Database model. - A database is a single collection of items (called entities) with variable properties (their attributes) which are organised (indexed) in a computerised file. There are several type of databases, viz. the flat-file database, the hierarchical database, the network database and the relational database $[8,9]$.

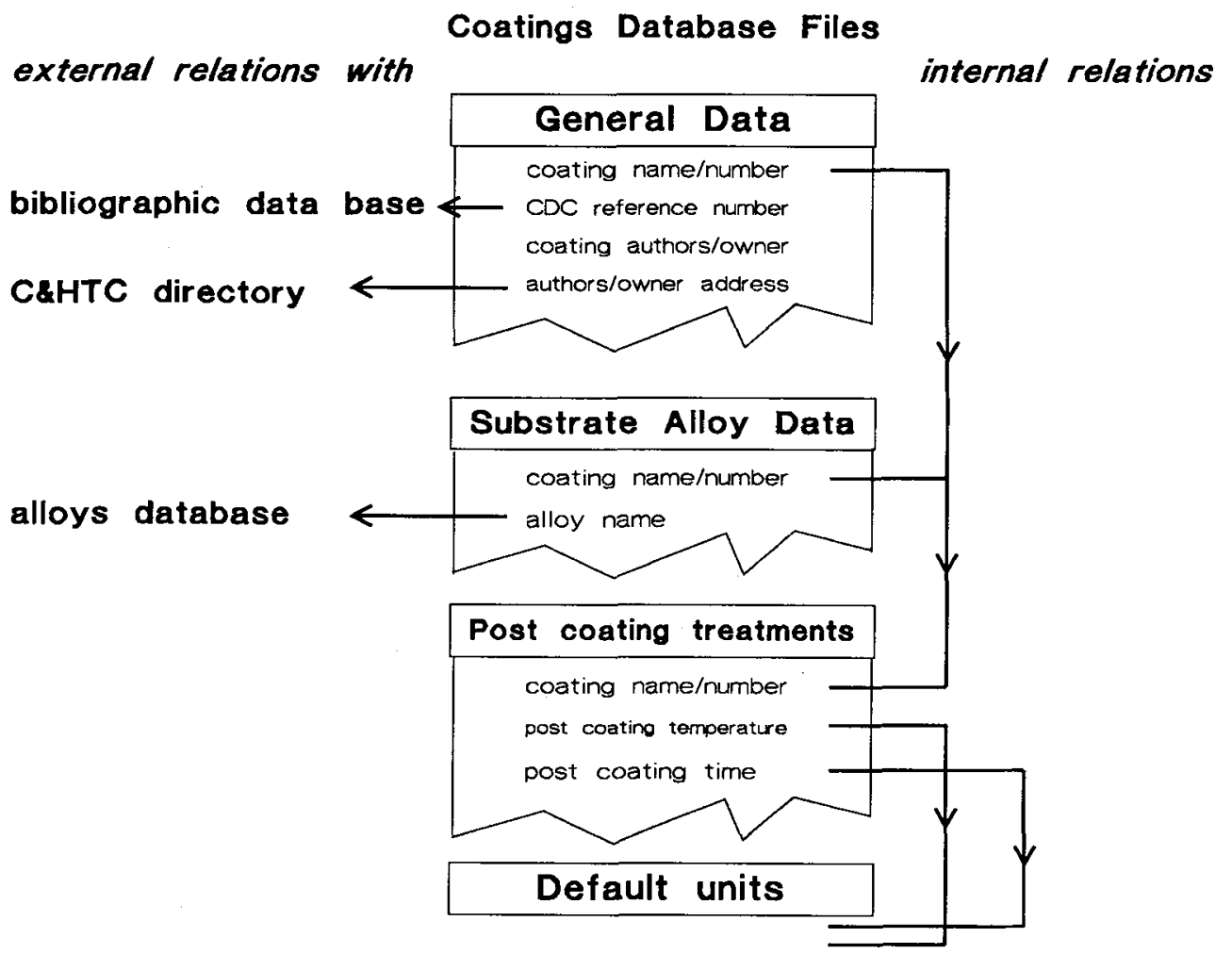

Fig. 1. - Connections in the relational database model.

In a recent review, the main features, advantages and drawbacks of these different kinds of database have been summarised [10]. It appears that the relational database, because of 
its high flexibility, is the most adapted model for a factual database such as the databases composing the coatings and high temperature corrosion bank.

A relational database is a database in which the conceptual files are all relations [11]. A relation is usually represented by a table. A table is composed of columns which are the attributes of the relation. Related items of single value or simple attributes constitute tuples; a tuple therefore corresponds to a line of the table. A relational database might be considered as a collection of flat-file databases (the tables) which are connected and a data bank usually is a collection of several databases. As illustrated in figure 1, each file (or table) of a relational database is connected with one or several of the other tables constituting the database, or with other databases, by one or more fields (attributes). This figure is a part of the file structure of C\&HTC-DATA coating database which has been published previously [6]. In this example, all the tables of the coating database are connected through the coating name field. Or the substrate alloy table is connected with the alloy database through the alloy name field.

The power and flexibility of the relational database model originate from this ability to connect the files using common fields. These connections can be defined and redefined to connect existing files as new relations are identified. Thus, new fields and new files can be added or deleted as needed very easily since this does not involve a modification of the database structure.

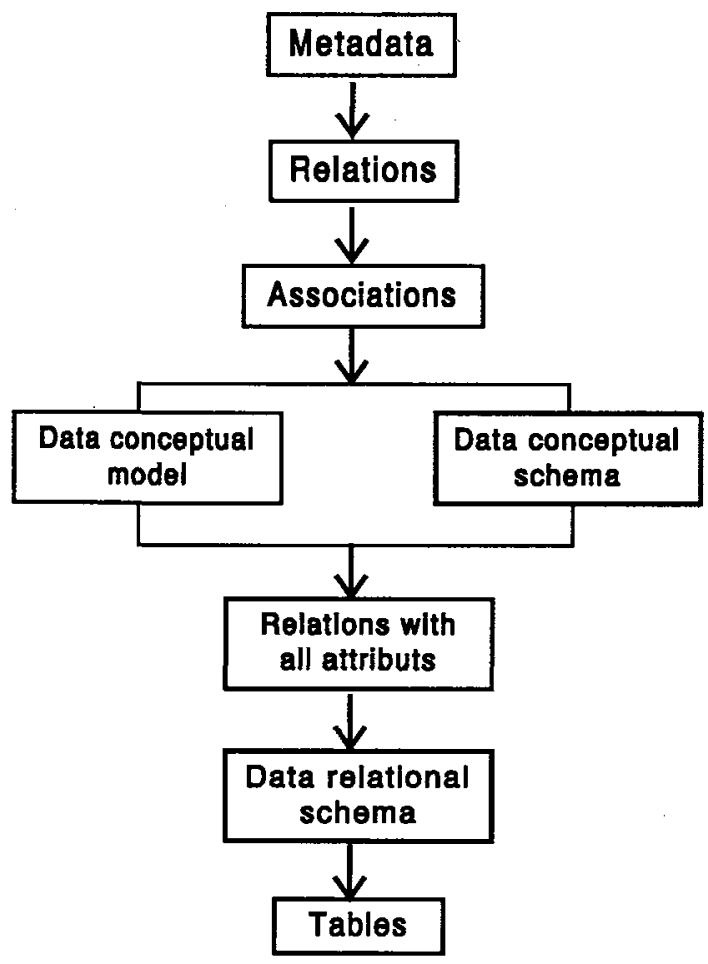

Fig. 2. - Data organisation for a relational database, following Merise's analytical treatment. 
3.2 DATA ORGANISATION DURING THE IMPLEMENTATION OF THE DATABASE. - When relations are established between single primary data, the database needs a special software to handle the data files. There are three common type of database management systems (DBMS) according to the three database models. We have chosen the ORACLE R.D.B.M.S. (relational database management system) because it is world-wide used and for its high portability.

There are a number of analytical methods to organise the data in an RDBMS. For C\&HTCDATA coating database, the MERISE method has been chosen [12]. The data organisation scheme for relational data using MERISE analytical treatment is represented in figure 2. The complete description of the successive stages of data development following this scheme is given in another paper in this Conference [13]. The data organisation scheme for relational data results in three structural representations of the data during the implementation of a database, viz. the data conceptual model (DCM)- which is the list of all the relations of the database; the data conceptual schema (DCS)- which is the schematic representation of the relations with all their associations, or link; and finally the data relational schema (DRS)which is the complete list of all the tables, with all the fields composing the database.

Figure 3 presents the Data Conceptual schema of the coating database, and table I gives the list of tables composing the database. There are 17 tables covering all aspects of coating deposition, characterisation and properties; plus one table which contains default units to be automatically inserted in field with metric data, and two tables from other databases of the data bank, viz. the alloy composition table, and the addresses from the directory. Table I includes also the views occurring in the database. A view is a part of a table, i.e. a number of fields which are displayed at the same time on the screen of the data bank. A table may be composed of several views or of one sole view.

Table II presents the COATING GENERAL DATA table as it appears in the DRS. In the DRS each of the table is represented with all its attributes, and with all the views composing this table. It is not possible to give in this paper all the 20 tables composing the coating database. Table II is therefore given as an example of data presentation in the DRS. The total number of fields amounts more than 250 , and a number of tables on deposition processes have not yet been completely documented. This demonstrates the complexity and the difficulty of building a factual database on coatings.

\section{Conclusion.}

This paper has given a general view of the data organisation by the relational database model, using a relational database management system, of a factual database on coatings. The data relational schema of the coating data base has been described in detail. It contains more than 250 fields which demonstrates the complexity of such a factual database. This coating database is part of C\&HTC-DATA, the coatings and high temperature data bank which has been created at the Université de Provence in Marseille (France). C\&HTC-DATA is currently composed of five databases four of which having been installed, i.e. the "coatings" database, the "alloys" database, the "bibliographic references" database and the "directory". Data from C\&HTC-DATA will be supplied by an "on-line" sever and the four installed databases are presently in a prototype stage for connection via the INTERNET international network. 


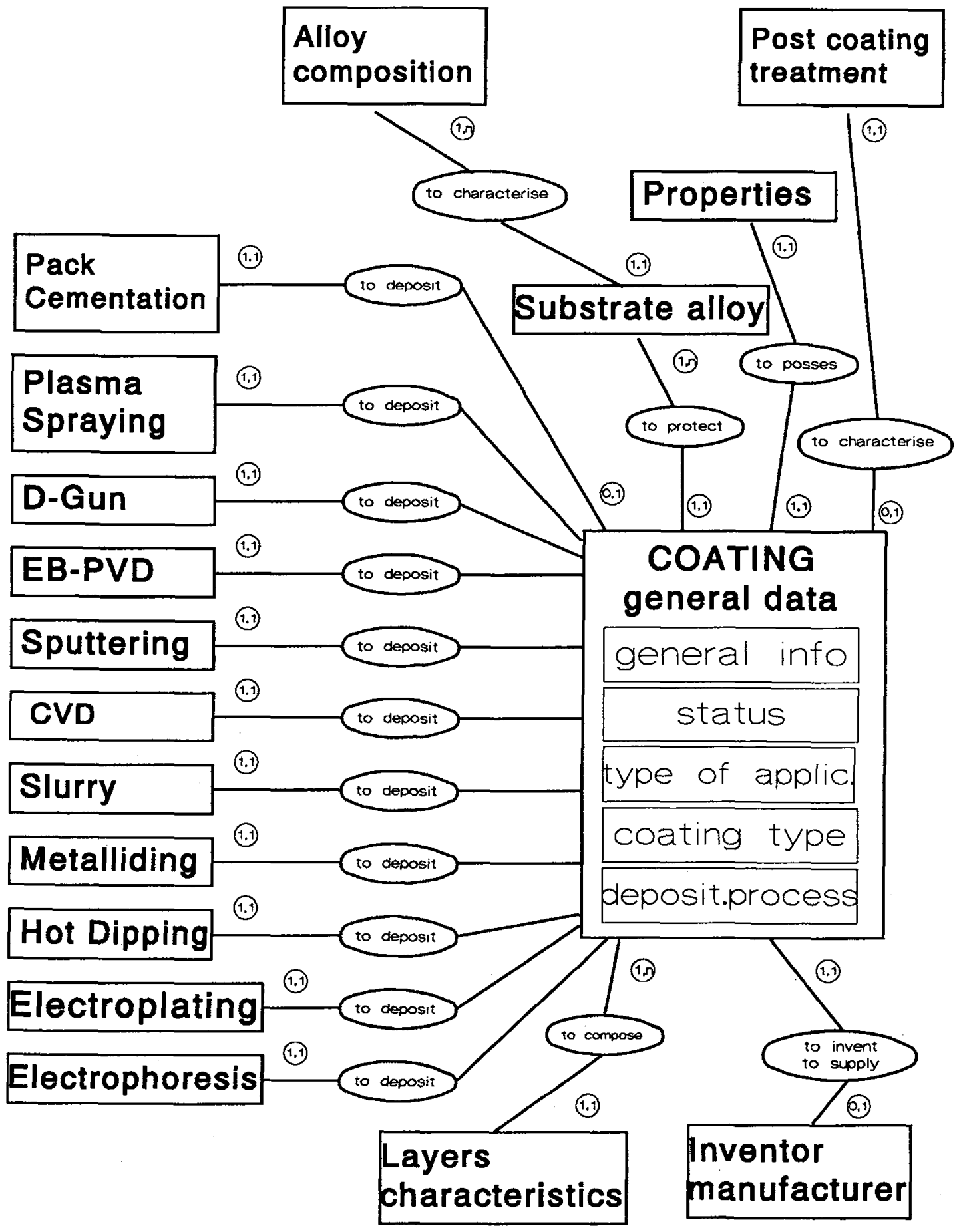

Fig. 3. - The DCS (data conceptual schema) of the coating database in C\&HTC data bank. 
Table I. - List of tables composing the views of the coating database.

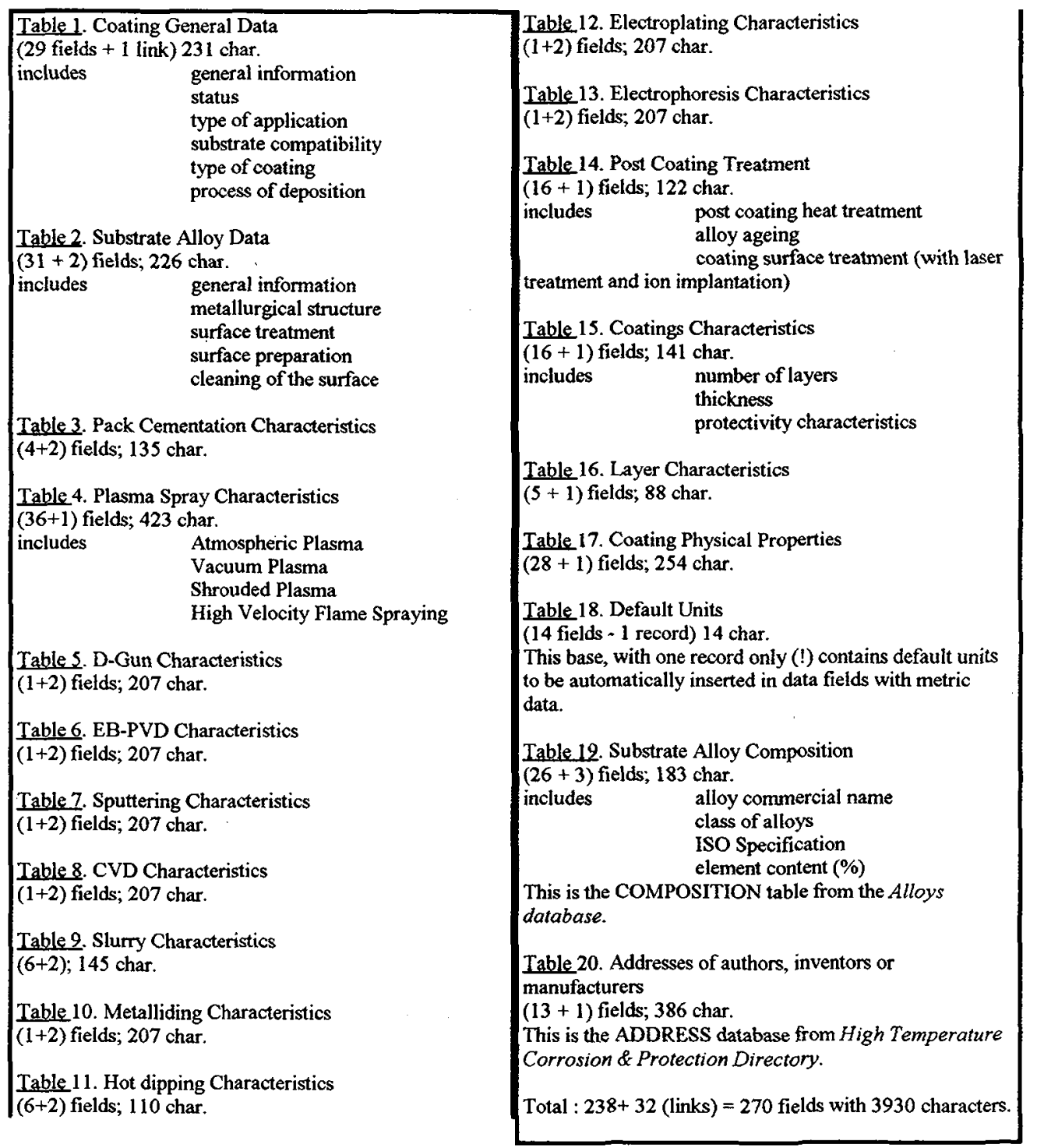

\section{Acknowledgements.}

The Coatings $\mathcal{E}^{2}$ High Temperature Corrosion Data Bank has been created thanks to support from French Ministry of Defence (D.R.E.T.), contract No 87/1458 and from French Ministry of Space and Research (D.I.S.T.) contract No 90.k.6441. A grant from E.P.R.I. (Palo Alto, CA U.S.A.), which permitted a sabbatical leave of one of the authors (R.S.) at the department of Materials Science \& Engineering at Stanford University during which this project was initiated, is also acknowledged. 
Table II. - Data representation of the COATING GENERAL DATA table in the DRS (Data Relational Schema) of the coating database.

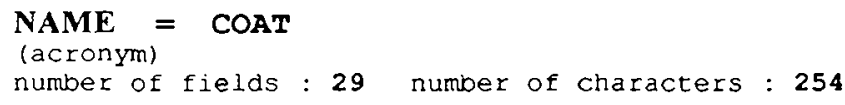

\section{Definition}

\section{COATING GENERAL DATA}

\begin{tabular}{ccc}
\hline Attributes : & Max. & Default \\
Name Option Format & $\begin{array}{c}\text { Maxth or } \\
\text { option } \\
\text { field name }\end{array}$ & defines \\
\hline
\end{tabular}

\begin{tabular}{|c|c|c|c|}
\hline \multicolumn{2}{|c|}{ VIEW NAME } & \multicolumn{2}{|c|}{ GENERAL } \\
\hline NCT \# & * & CHAR & 2 \\
\hline NN & 0 & NUM & \\
\hline OEM & 0 & CHAR & \\
\hline OEMS & 0 & CHAR & \\
\hline ISDATE & 0 & DATE & \\
\hline SDOC & 0 & CHAR & \\
\hline STYP & 0 & CHAR & \\
\hline MAN & 0 & CHAR & \\
\hline ADDR & 0 & CHAR & \\
\hline VIEW & $\mathbf{M E}$ & STATU & \\
\hline STC & + & CHAR & \\
\hline STD & + & CHAR & \\
\hline STR & + & CHAR & \\
\hline
\end{tabular}

coating name(20) and number(6) CDC reference number

Original Equipment Manufacturer OEM SpeC.

date of issue source document source document type inventor or owner of technology OWNER address code

\begin{tabular}{|c|c|c|}
\hline TVA & + & CHAR \\
\hline TBL & + & CHAR \\
\hline TCO & + & CHAR \\
\hline TBU & + & CHAR \\
\hline TOT & 0 & CHAR \\
\hline NSAI & 0 & NUM \\
\hline
\end{tabular}

VIEW NAME : SUBSTRATE COMPATIBILITY

\begin{tabular}{l|ll} 
STR & + & CHAR \\
TVA & + & CHAR \\
TBL & + & CHAR \\
TCO & + & CHAR \\
FEC & + & CHAR \\
NIC & + & CHAR \\
COC & + & CHAR \\
OBC & + & CHAR \\
VIEW NAME & TYPE OF
\end{tabular}

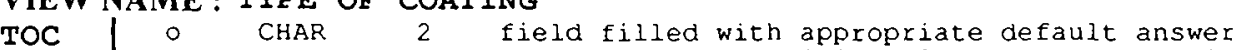

(logical T/E) STATUS - commercial

1 (logical $\mathrm{T} / \mathrm{E}$ ) STATUS - research

APPLICATION

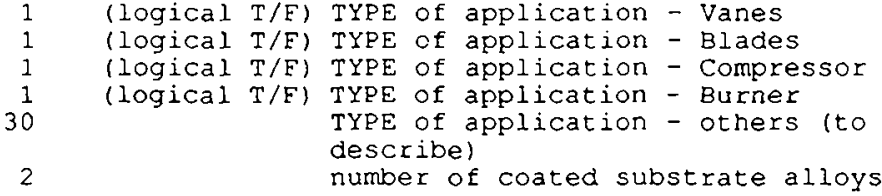

$1 \quad(\operatorname{logical} T / F)$

(logical $T / F)$

(logical $T / F)$

$(\operatorname{logical} \mathrm{T} / \mathrm{F})$

(logical $T / E$ ) iron alloys compatibility

(logical $T / F$ ) nickel alloys compatibility

(logical $\mathrm{T} / \mathrm{F}$ ) cobalt alloys compatibility (logical $\mathrm{T} / \mathrm{E}$ ) other alloys compatibility 1 letter for unmodified; 2 letters for modified coatings

$\begin{array}{lll}+ & \text { CHAR } & \text { (ALM) } \\ + & \text { CHAR } & \text { (MAL) } \\ + & \text { CHAR } & \text { (PTM) } \\ + & \text { CHAR } & \text { (PDM) } \\ + & \text { CHAR } & \text { (SIM) } \\ + & \text { CHAR } & \text { (YTM) } \\ + & \text { CHAR } & \text { (REM) } \\ + & \text { CHAR } & \text { (CRM) } \\ + & \text { CHAR } & \text { (MCR) } \\ + & \text { CHAR } & \text { (SIN) } \\ + & \text { CHAR } & \text { (MSI) } \\ + & \text { CHAR } & \text { (OVL) } \\ + & \text { CHAR } & \text { (INM) } \\ + & \text { CHAR } & \text { (CER) } \\ + & \text { CHAR } & \text { (TBC) }\end{array}$

$A$
$M H$
$M P$
$M D$
$M S$
$M Y$
$M R$
$H$
$H M$
$S$
$S M$
$O$
$I$
$C$
$T$

o optional

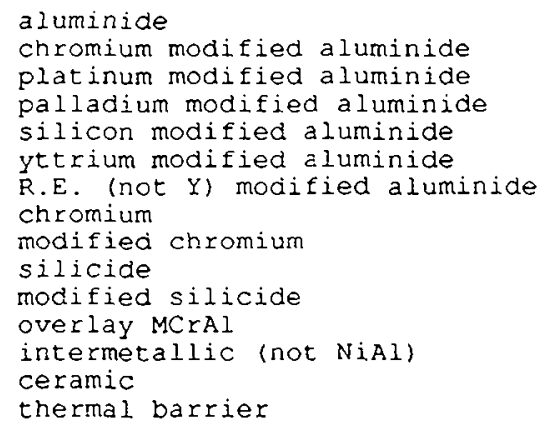

\# primary key * non optional
+ default value 


\section{References}

[1] STREIFF R. (this Conference).

[2] 1st Inter. Symposium on High Temperature Corrosion of Materials and Coatings for Energy Systems and Turboengines, Marseille (July 7-9, 1986); 2nd Inter. Symposium on High Temperature Corrosion of Advanced Materials and Coatings, Les Embiez (May 22-25, 1989); 3rd Inter. Symposium on High Temperature Corrosion and protection of Materials, Les Embiez (May 25-29, 1992).

[3] STREIFF R., Mat. Charact. 27 (1991) 261-268.

[4] STREIFF R., in Computerization and Networking of Materials Databases: Second Volume, J.G. Kaufman and J.S. Glazman Eds., American Society for Testing and Materials (ASTM STP 1106, Philadelphia, 1991) pp. 251-258.

[5] STREIfF R., KOMORNiCKI S., in Proceed. Life Assessment \& Repair Technology for Combustion Turbine Hot Section Components, R. Viswanathan and J.M. Allen Eds. (ASM International Publ., Materials Park, Ohio USA, 1990) pp. 245-252.

[6] STREIFF R., KOMORNICKI S., Surf. Coat. Technol. 50 (1992) 263-269.

[7] BUTTNER P., RAULS W., "Materials Data-Bases" comm. presented at AFNOR/CODATA Workshop, Paris, Nov. 8, 1988.

[8] Ullman J.D., Principles of database and knowledge-base systems (Computer Science Press publ. Rockville U.S.A., 1988).

[9] PASLeAU S., "Le livre de SQL" (Editions P.S.I., Paris, 1989) pp. 21-25.

[10] STREIfF R., Corros. Sci. 35 (1993) 1177-1187.

[11] CoDd E.F., "A Relational Model of Data for Large Shared Data Banks", Commun ACM 26 (1983) 377-387.

[12] DIvINE M., "Parlez vous MERISE ?" (Editions Eyrolles, Paris, 1989).

[13] VAUGELADE S., STREIFF R., to be published. 